\title{
Automation of monitoring students' knowledge and independent work using Mathcad
}

\author{
Marina Batova \\ Department of Informatics and Management \\ Military University of the Ministry of Defence of the Russian Federation \\ 125047, Bolshaya Sadovaya street, 14, \\ Moscow, Russia \\ batova_m_m@mail.ru
}

\begin{abstract}
In the challenging Covid-19, and also online education and web-learning expansion conditions, independent and distance forms of student work become especially relevant. As a consequence, the role played by such important parts of the educational process as control and monitoring the knowledge acquisition by students, and also their skills and abilities is growing. In this connection, the need to provide the educational process with a large number of individual variants of tasks, both training tasks and control tests, has increased. In addition, in this case a teacher faces the problem on performing such timeconsuming work as quick checking and evaluating a large number of tasks completed by students, and also monitoring their knowledge and skills. To solve these problems, the paper offers an automated method for creating and checking tasks and tests using Mathcad software. Implementation of this method is shown by an example of topics studied in the courses "Econometrics" and "Mathematical Statistics". The author has a patent issued by the Federal Service for Intellectual Property of the Russian Federation for the developed algorithm.
\end{abstract}

Keywords - Automated knowledge control, automated test task creation, econometrics, Mathcad.

\section{INTRODUCTION}

$\mathrm{N}$ EW external environment challenges due to the turbulent Covid-19 period, digital transformation of society and education, online education and web-learning expansion lead to the fact that the traditional education model, where the knowledge acquisition and translation processes, and also students working in a classroom with a teacher dominated, becomes uncompetitive [1]. Integration of education and information technologies, innovative approaches in education, synergy of new educational technologies and established pedagogical practices are coming to the fore. Such learning forms as students' independent work and remote interaction with a teacher become especially relevant (Figure 1).

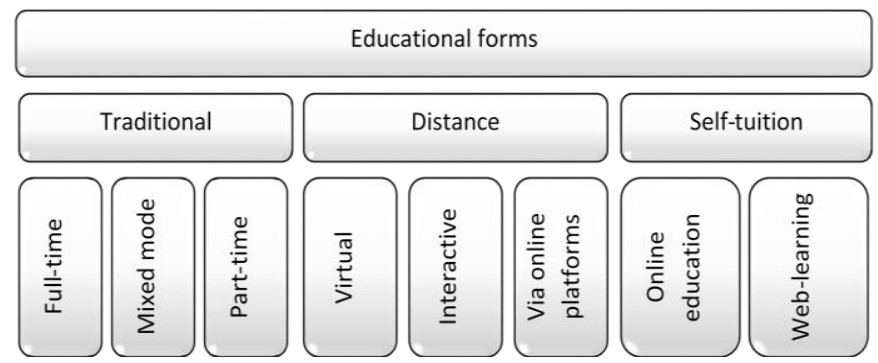

Figure 1: Main educational forms

Source: author's research.

Thus, in today's reality, educational space cannot be limited to classrooms and university walls, and it is very extensive and flexible. In previous works, the author proposed to consider the integrated educational environment model as the one involving the creation of a common virtual learning, methodological and event space for all educational process participants in order to organize effective interaction between subjects of this system within the framework of educational and scientific work, as well as additional educational activities [1].

This model integrates both new technologies and innovative approaches to learning and does not negate traditional technologies, established practices, and proven techniques, but takes from them the best time-tested approaches and techniques, thinking about them in a new way and implementing in new innovative learning models (Figure 2). In addition, new and traditional forms of learning combine and complement each other in an integrated learning space. The result is not just the sum of new and traditional technologies and forms of learning, but their synergy. As a consequence, this synergetic effect leads to the education quality improvement, and also to new competences possessed by future specialists. 


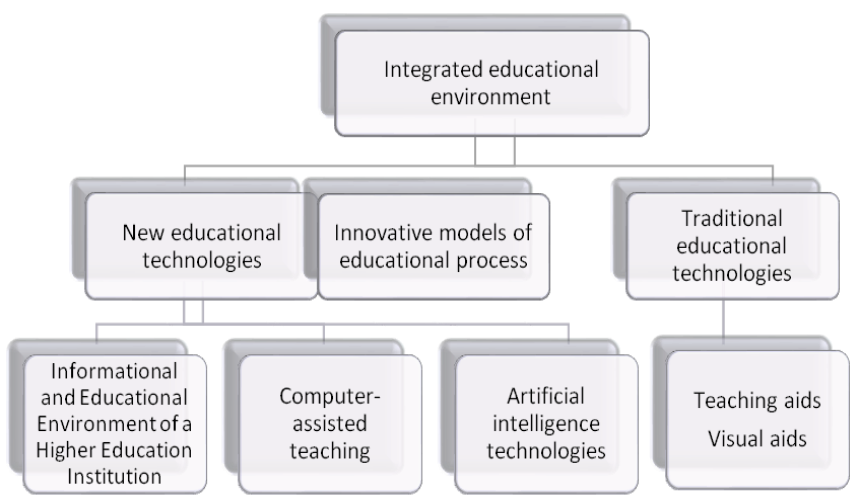

Figure 2: Integrated educational environment model Source: author's research.

Thus, in the current context of integrated educational environment, online education, distance learning, orientation to competence-based approach, the role of students' independent development and training of skills, and also selfmonitoring of their knowledge increases. In addition, the importance and significance of students' knowledge control and monitoring, checking and evaluation by a teacher are increasing.

\section{PRoblem STAtement}

The aim of any learning activity, in whatever form and setting it could be performed, is ultimately knowledge and skills acquisition. As a result of higher education, students should acquire the necessary competences. Therefore, an important part of any educational process is, firstly, training and practicing skills, and secondly, checking and controlling (monitoring) students' mastering of knowledge, skills and abilities [2, 3, 6, 11].

Monitoring, checking and evaluation of students' knowledge are necessary for their university and also for their teachers, as well as for the students themselves. Universities and teachers need to identify the knowledge level and to assess the learning results of their students, as well as to check the effectiveness demonstrated by methods and techniques of their scientificmethodical and pedagogical work [3]. On the other hand, students need to train their skills, measure their progress, assess their knowledge quality, and intensify their mental activity [3, 4, 5 11]. All this is achieved by systematic independent performance of different kinds of tasks, tests, and projects.

Types and methods for training and monitoring students' knowledge can be different [3, 4]. As for mathematical disciplines, particularly econometrics, the most relevant and applicable is a written and/or electronic training and monitoring in the form of individual assignments for calculations, projects, and tests $[5,7,11]$.

This type of monitoring has a number of advantages:

- Large coverage of students;

- Objectivity and comprehensiveness,

- Set time limits for completion,
- The possibility for students to distribute the order of the tasks and the time allocated in a convenient way, i.e. students are free to choose their own algorithm of actions; etc.

However, this type of monitoring also has a significant disadvantage. It is an unreasonably large amount of work for a teacher, which is expressed in:

- The need for more thorough preparation;

- The creation of a large number of individual student assignments and the verification of these assignments for incorrectness;

- The time-consuming verification and assessment of a large volume of completed student work.

Thus, the teacher faces several major challenges, especially intensified in online learning.

The first problem is how to provide individual assignments for a large number of students, for several study groups or for the whole course. In particular, in Russian universities, the average number of students in a study group is $25-30$, and the number of students per course can exceed 100.

The availability of a large number of individual assignments becomes especially relevant in distance learning. In this case, it has the following objectives:

- To ensure additional preparation and self-study by students before upcoming tests and exams;

- To exclude illegitimate assistance of others in completing tests and quizzes, i.e. cheating by students ("copying other's works") on exams.

Secondly, assignments and tests for training, self-assessment and monitoring should be valid tools for assessing students' knowledge [3] and comply with basic methodological principles [12]. That is, task and test options should be typical in terms of their difficulty and be uniform for all students. Thus, a university teacher is faced with the problem of how to find and select such a large number of tasks that meet the requirements of teaching methodology.

Thirdly, a teacher has to conduct a thorough analysis and evaluation for such a large number of calculations, projects and tests performed by students. This is a very time-consuming and labour-intensive part of the teacher's work. The teacher is faced with the problem on how to ensure that this work is done both promptly and efficiently without wasting time and effort?

Thus, the aim of this research was to develop an automated approach to solve the above-mentioned problems and challenges that arise during the training and monitoring of students' knowledge, skills and abilities, with a focus on the applicability of this approach in online education and webbased learning.

The tasks can be solved by automating the teacher's work, such as creating and checking the tests and quizzes. The paper proposes an approach to automatic task modelling using computer systems and application packages $[5,8,9,10,16]$. 


\section{PROBLEM SOLUTION}

\section{A. Automated task creation}

In this research, the way for solving the problems has been developed using the Mathcad software package (website www.mathcad.com) [15].

In this aspect, the Mathcad use is considered for the following purposes:

- To create a large number of individual variants for a test work according to specified conditions,

- To select and verify the generated tasks,

- For the subsequent verification of these tasks by the students.

This concerns the courses "Econometrics" and "Mathematical Statistics", for which the author deliver lectures and conducts practical classes in Russian universities. The main stages of the automated test development and solution checking are presented in Figure 3.

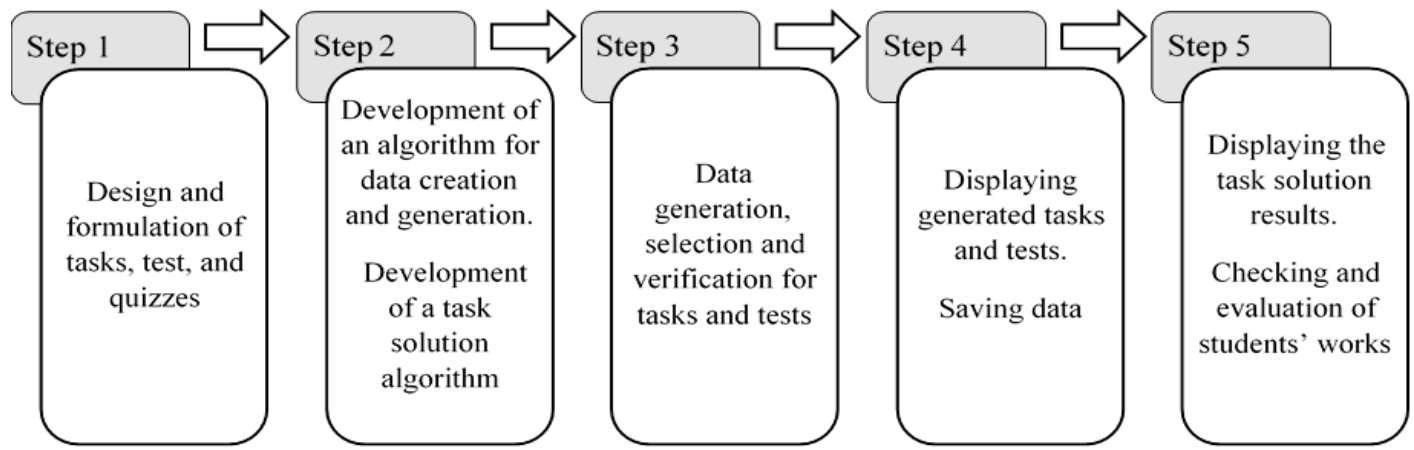

Figure 3: Flowchart for the development of automated test tasks modelling using MathCad.

Source: author's research.

The research provides an example of automated test creation and checking for one of the topics studied in "Econometrics" and "Mathematical Statistics", namely Linear Pair Regression [13, 14].

In accordance with the syllabus, typical test tasks on this topic include the study of a linear relationship between two economic variables $Y$ and $X$. Namely, one should perform the following in the test:

- Estimation of the correlation between variables $Y$ and $X$,

- Estimation of the regression equation parameters,
- Estimation of statistical significance and regression quality using Student $t$-test and Fisher $F$-test,

- Model approximation estimation,

- Calculation of predicted values.

The task text is the same for all students. In the process of creating the algorithm, the teacher himself enters it on Mathcad sheet. Then numerical values of the generated samples are output (inserted) in the text automatically as a result of the created algorithm. Figure 4 exemplifies the completed version of a test task with its displaying.

\begin{tabular}{|c|c|c|c|c|c|c|}
\hline \multicolumn{7}{|r|}{ Test on Linear Pair Regression } \\
\hline \multicolumn{7}{|r|}{ Variant $\mathrm{v}=5$} \\
\hline \multicolumn{7}{|c|}{ Study a relationship between economic variables $Y$ and $X$. Sample data is given. } \\
\hline \multirow{13}{*}{$y=$} & & 1 & \multirow{13}{*}{$\mathrm{x}=$} & & & \multirow{13}{*}{$\begin{array}{l}\text { Do: } \\
\text { 1) Construct an equation for linear pair regression of the dependence of the } \\
\text { variable } Y \text { on the factor } X \text {. Explain the economic meaning of its parameters. } \\
\text { Represent the resulting relationship graphically and the correlation field. } \\
\text { 2) Estimate the closeness of the linear relationship between the variable } Y \\
\text { and factor } X \text { using correlation and determination coefficients. Estimate the } \\
\text { statistical significance of the correlation coefficient and regression } \\
\text { coefficients at the significance level } 0.05 \text { (use t-test). } \\
\text { 3) Estimate the statistical reliability and quality of the resulting regression } \\
\text { equation using both the Fisher's F-test and the average approximation error. } \\
\text { 4) Calculate the average coefficient of elasticity and use it to estimate the } \\
\text { strength of the relationship between the variable } Y \text { and the factor } X \text {. } \\
\text { 5) Calculate the prediction value of the variable } Y \text { if the value of factor } X \\
\text { increases by } 10 \% \text { from its mean. Find the confidence interval of the forecast } \\
Y \text { at the significance level } 0.05 \text {. }\end{array}$} \\
\hline & 1 & 8 & & 1 & 16 & \\
\hline & 2 & 9 & & 2 & 18 & \\
\hline & 3 & 9 & & 3 & 14 & \\
\hline & 4 & 8 & & 4 & 14 & \\
\hline & 5 & 11 & & 5 & 18 & \\
\hline & 6 & 8 & & 6 & 16 & \\
\hline & 7 & 10 & & 7 & 20 & \\
\hline & 8 & 9 & & 8 & 14 & \\
\hline & 9 & 12 & & 9 & 19 & \\
\hline & 10 & 8 & & 10 & 14 & \\
\hline & 11 & 10 & & 11 & 19 & \\
\hline & 12 & 10 & & 12 & 14 & \\
\hline
\end{tabular}

Figure 4: Example of an automated test variant display for the "Linear Pair Regression" topic. Source: author's research. 
In this research, an algorithm was developed for the automated creation of a large number of variants for tasks and tests in the Mathcad software environment for a Linear Pair Regression. An example of the implementation of this algorithm is illustrated in Figure 5.

1) The Mathcad software environment generates a matrix of values for a factor $x_{i j}$. It is possible to specify the required number of test tasks $k$ and the required amount of data, i.e. $n$ values of variables $X$ and $Y$. The function of random number generation is used for creating the $x_{i j}$ matrix. The distribution law can be chosen at the user's discretion (normal, binomial, exponential, etc.). The example shown in Figure 5 uses the uniform distribution law runif $(\mathrm{n}, \mathrm{C}, \mathrm{d})$, where $c$ and $d$ are interval bounds. These can also be set at the user's discretion. If necessary, the numeric data can be rounded to the required order using the round $<>$ function. The example is rounded to a whole number.

2) Then, depending on the purpose of the tasks (test) or the content of the studied variables $X$ and $Y$, the starting values for the linear pair regression coefficients $a$ and $b$ are set.

3) Next, a vector column of random deviations (random components) $\varepsilon$ is generated. In accordance with the conditions of the Gauss-Markov theorem [13, 14], a function of random numbers distributed according to a normal law with a given value $\mu=0$ and a constant standard deviation $\sigma$ $\operatorname{rnorm}(n, \mu, \sigma)$ is used for this purpose. It should be noted that if the training process is aimed at mastering the skills of detecting breakdowns of Gauss-Markov theorem assumptions, in this case the developed algorithm can be promptly provided with necessary corrections:

- Changing the distribution law to another one described by a Mathcad function available,

- Changing the parameters of a normal distribution law, e.g. by arbitrarily setting mean value $\mu$ not equal to zero,

- Or setting the standard deviation law $\sigma$ so that the value $\sigma$ would not be constant.

4) Then a matrix of values for the dependent variable $y_{i j}$ is generated. This is done using the formula of the Linear Pair Regression model, the rounding function, the specified values of the regression parameters $a$ and $b$, the generated values of the factor $x_{i j}$ and the random component $\varepsilon_{j}$ : round $<\left(a+b \cdot x_{j}+\varepsilon\right)>$.

5) Thus, on the basis of generated $k$ datasets, which are samples of the given volume $n$, the required number of $k$ versions of tasks (tests) which satisfy both learning objectives and the given economic conditions of the tasks is created. The tasks are ready for their use.

As it has been shown, the created algorithm provides that users can assign the number of variants and the volume of the generated samples at their discretion in the quantity that they need. Figure 5 shows an example of sample generation in the case where the volume is $n=12$, and for $k=10$ variants.

\section{MODELLING OF TEST ON LINEAR PAIR REGRESSION}

Parameter Input

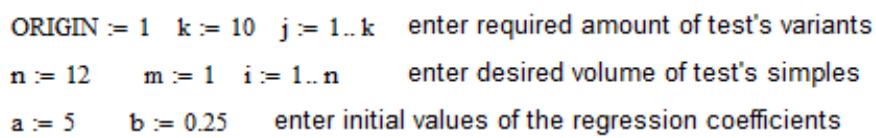

Modelling Numeric Values for Test's Variants

$\mathrm{x}_{\mathrm{j}}:=\operatorname{round}(\operatorname{runif}(\mathrm{n}, 13,20)) \quad \varepsilon_{\mathrm{j}}:=\operatorname{morm}(\mathrm{n}, 0,1) \quad \mathrm{y}_{\mathrm{j}}:=\operatorname{round}\left(\left(\mathrm{a}+\mathrm{b} \cdot \mathrm{x}_{\mathrm{j}}+\mathrm{z}_{\mathrm{j}}\right)\right)$

$$
\mathrm{Y}^{\langle\mathrm{j}\rangle}:=\mathrm{y}_{\mathrm{j}} \quad \mathrm{X}^{\langle\mathrm{j}\rangle}:=\mathrm{x}_{\mathrm{j}}
$$

Output of Numeric Values for Test's Variants

Samples for Test's Variants

\begin{tabular}{|r|r|r|r|r|r|r|r|r|r|r|}
\hline & 1 & 2 & 3 & 4 & 5 & 6 & 7 & 8 & 9 & 10 \\
\hline 1 & 9 & 8 & 9 & 9 & 8 & 8 & 9 & 8 & 8 & 8 \\
\hline 2 & 9 & 8 & 10 & 10 & 9 & 10 & 10 & 11 & 8 & 9 \\
\hline 3 & 9 & 8 & 12 & 8 & 9 & 8 & 10 & 8 & 10 & 10 \\
\hline 4 & 9 & 8 & 9 & 8 & 8 & 10 & 9 & 7 & 9 & 9 \\
\hline 5 & 10 & 9 & 7 & 8 & 11 & 7 & 10 & 10 & 10 & 10 \\
\hline 6 & 9 & 9 & 8 & 9 & 8 & 9 & 10 & 8 & 10 & 10 \\
\hline 7 & 9 & 10 & 8 & 8 & 10 & 10 & 9 & 8 & 10 & 10 \\
\hline 8 & 8 & 9 & 9 & 6 & 9 & 7 & 10 & 9 & 9 & 10 \\
\hline 9 & 12 & 9 & 8 & 10 & 12 & 10 & 10 & 9 & 9 & 10 \\
\hline 10 & 8 & 8 & 8 & 10 & 8 & 10 & 9 & 8 & 9 & 10 \\
\hline 11 & 9 & 11 & 9 & 10 & 10 & 10 & 10 & 8 & 9 & 9 \\
\hline 12 & 9 & 10 & 10 & 7 & 10 & 9 & 10 & 10 & 9 & 10 \\
\hline
\end{tabular}

\begin{tabular}{|l|l|l|l|l|l|l|l|l|l|l|}
\hline & 1 & 2 & 3 & 4 & 5 & 6 & 7 & 8 & 9 & 0 \\
\hline 1 & 13 & 13 & 19 & 16 & 16 & 18 & 16 & 14 & 18 & 14 \\
\hline 2 & 14 & 17 & 18 & 18 & 18 & 15 & 20 & 15 & 17 & 14 \\
\hline 3 & 17 & 17 & 20 & 16 & 14 & 18 & 18 & 15 & 16 & 20 \\
\hline 4 & 15 & 14 & 17 & 18 & 14 & 18 & 14 & 14 & 18 & 19 \\
\hline 5 & 19 & 16 & 15 & 17 & 18 & 14 & 19 & 19 & 16 & 15 \\
\hline 6 & 14 & 13 & 19 & 18 & 16 & 19 & 17 & 17 & 17 & 16 \\
\hline 7 & 18 & 18 & 16 & 17 & 20 & 17 & 13 & 15 & 17 & 17 \\
\hline 8 & 15 & 17 & 18 & 14 & 14 & 16 & 17 & 13 & 17 & 16 \\
\hline 9 & 14 & 19 & 13 & 16 & 19 & 20 & 17 & 19 & 18 & 17 \\
\hline 10 & 14 & 20 & 15 & 17 & 14 & 17 & 19 & 14 & 14 & 19 \\
\hline 11 & 20 & 17 & 17 & 18 & 19 & 16 & 18 & 17 & 14 & 17 \\
\hline 12 & 14 & 16 & 19 & 14 & 14 & 19 & 19 & 14 & 16 & 17 \\
\hline
\end{tabular}

Figure 5: Automated task variant creation algorithm and an example of its implementation when studying the "Linear Paired Regression" topic.

Source: author's research 
In this example, the data are generated according to the basic conditions of the Gauss-Markov theorem regarding random components $\varepsilon$ :

- They are uncorrelated between each other;

- They are distributed according to a normal law with zero mathematical expectation;

- Their variance is constant (homoscedasticity condition).

The variance for this $\varepsilon$ is set to $\sigma=1$ in order to obtain sufficient variation in the generated data for the dependent variable $Y$, which in turn allows for diverse and significantly different samples at the output. The regression coefficient $b$ has been assigned a positive value of 0.25 in order to ensure that the generated data are positively correlated.

All the described parameters can be assigned by a user (teacher or student) in accordance with the objectives of their work, and change them if necessary.

That is, the developed algorithm is interactive, which is especially important for students in online learning.

The output is a matrix of generated data for variables $Y$ and $X$, where the column represents the variant number. A sample corresponding to the assigned variant number is then extracted from these matrices and displayed as a task.

If the variable $v$ value is assigned equal to the variant number, the task text is displayed with automatically inserted generated data samples for variables $Y$ and $X$. Figure 4 shows variant number $5(v=5)$. When the user change the value $v$, the corresponding variant of the generated data is displayed.

\section{B. Automated task solution and its displaying on a screen}

Further, in order to reduce the labour-intensiveness and time spent by a teacher on checking the test tasks completed by the students, an algorithm is created in the same file of MathCad software environment for solving and calculating the generated variants of the task. The results of calculations and answers of all stages of test tasks are displayed on the screen. This is also necessary so that the teacher could review the generated samples and the solutions obtained from them before issuing tasks to students to make sure there are no incorrect data.

Displaying the solution results is implemented as follows.

1) First, the created algorithm calculates vector columns for parameters common to all variants of the test:

- Mean values for variables $X$ and $Y$ using the function mean $\left(x_{j}\right)$,

- Standard deviations for $X$ and $Y$ using the function $\operatorname{stdev}\left(x_{j}\right)$,

- Regression coefficients $a$ and $b$ using the function line $\left(x_{j}, y_{j}\right)$

- Correlation coefficients $r$ and determination coefficient $R^{2}$, using their properties and the function $\operatorname{corr}\left(\mathrm{y}_{j}, \mathrm{x}_{j}\right)$,

- $t$-test for correlation coefficients using the given formulas,

- $F$-rest using the given formula,

- $E l$ elasticity coefficient using the given formula.

Figures $6 \mathrm{a}$ and $6 \mathrm{~b}$ show the operation of this algorithm and an example of its implementation.

2) The algorithm then performs the calculations separately and individually for each variant. When a variant number is entered, the algorithm outputs calculation results using the given formulas for:

- The modelled values of the dependent variable $Y$,

- Random deviations $e$ of the model,

- $\quad$ t-test for regression coefficients $a$ and $b$,

- Mean approximation error $A$

The algorithm also constructs a correlation field and a trend line.

Figure 7 shows the operation of the algorithm for these calculations and an example of their implementation for one of the created task variants $(v=5)$.

3) At the end of the calculation, the developed algorithm calculates the predicted values with a confidence interval according to the given rules and formulas (Figure 8).

\section{Storing and displaying the generated variants of tasks} and tests

MathCad has a function that updates the results of data generation and calculations each time we open the file [15]. On the one hand, this is a positive feature, because each time we open the file, we get a new set of task and test variants. But on the other hand, it is a disadvantage because we then lose the previous generated task data, and the results of their solutions as well as the answers that the teacher has to use to check the tests performed by the students.

Therefore, in order to eliminate this disadvantage, data storage, solutions of the generated tests and the method to display them on the screen are organized in the algorithm. For this purpose, the generated data are written to a text file using the WRITEPRN ("filename") function [15] and stored there. An important condition is that this file must be located in the same directory as the file for creating and solving test tasks.

Further, in order to display the generated set of variants of tasks or print it out, and to use the calculations and answers to check student solutions, the algorithm organises this procedure using the READPRN ("filename") function [15]. Then generated datasets and tasks will be read from the saved text data file and displayed on the screen. If the required variant number is assigned, its data will be read from the file, used to calculate the solution and obtain the answers, which in turn will be fully displayed on the screen.

Figure 6a shows the use and operation of the WRITEPRN and READPRN functions.

These procedures, on the one hand, allow a teacher to automate the training of skills and monitoring of students' knowledge, while reducing labour and time costs. On the other hand, they allow students to receive and store the variants of the training tasks, self-training and self-monitoring of their knowledge and skills during online learning. 


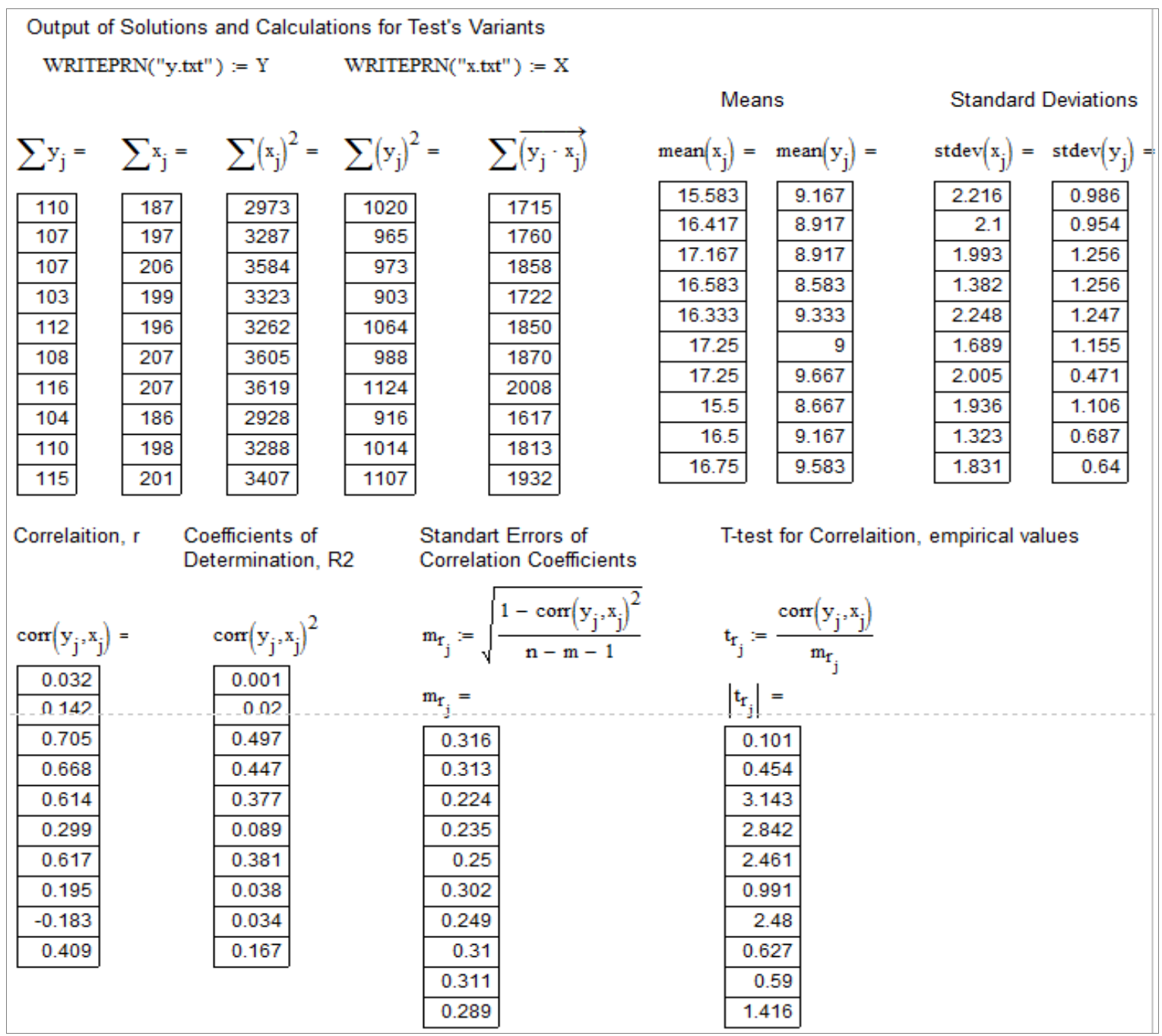

Figure 6a. Automated solution algorithm for the created tasks and its implementation example for common calculations of all variants, part 1.

Source: author's research.

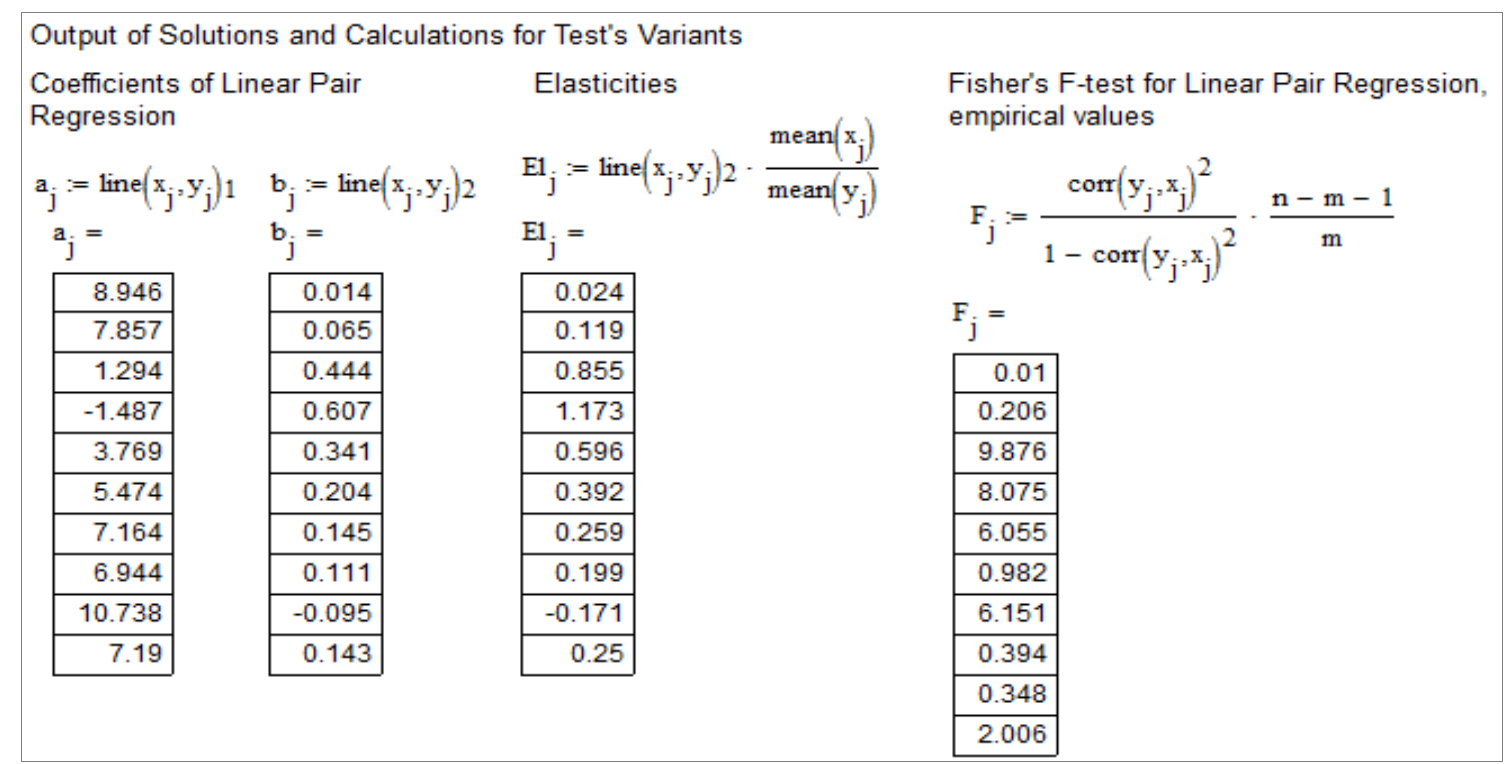

Figure 6b. Automated solution algorithm for the created tasks and its implementation example for common calculations of all variants, part 2.

Source: author's research. 
INTERNATIONAL JOURNAL OF EDUCATION AND INFORMATION TECHNOLOGIES

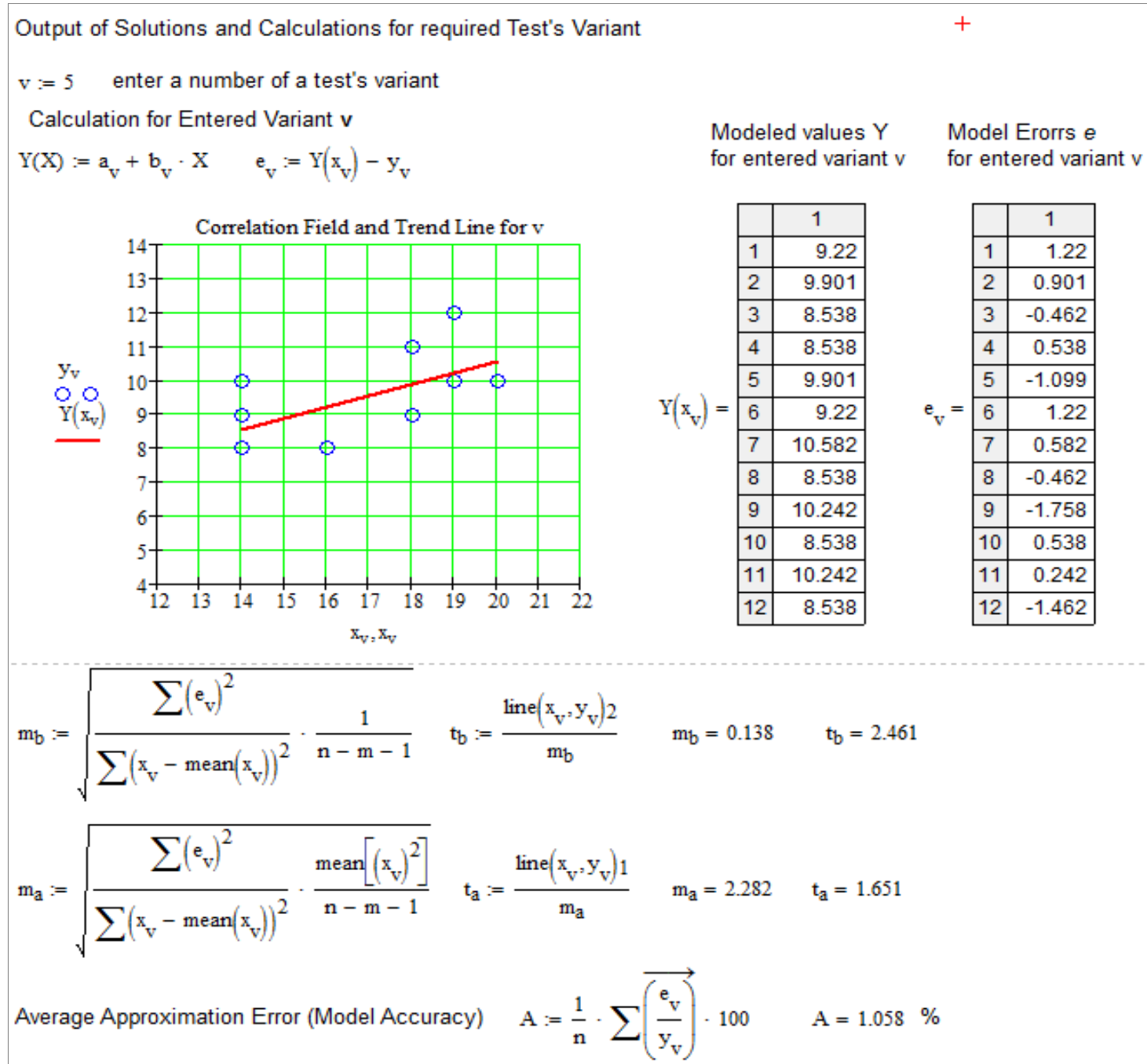

Figure 7. Algorithm for the automated solution of the created tasks and an example of its implementation for calculating the required variant individually.

Source: author's research.

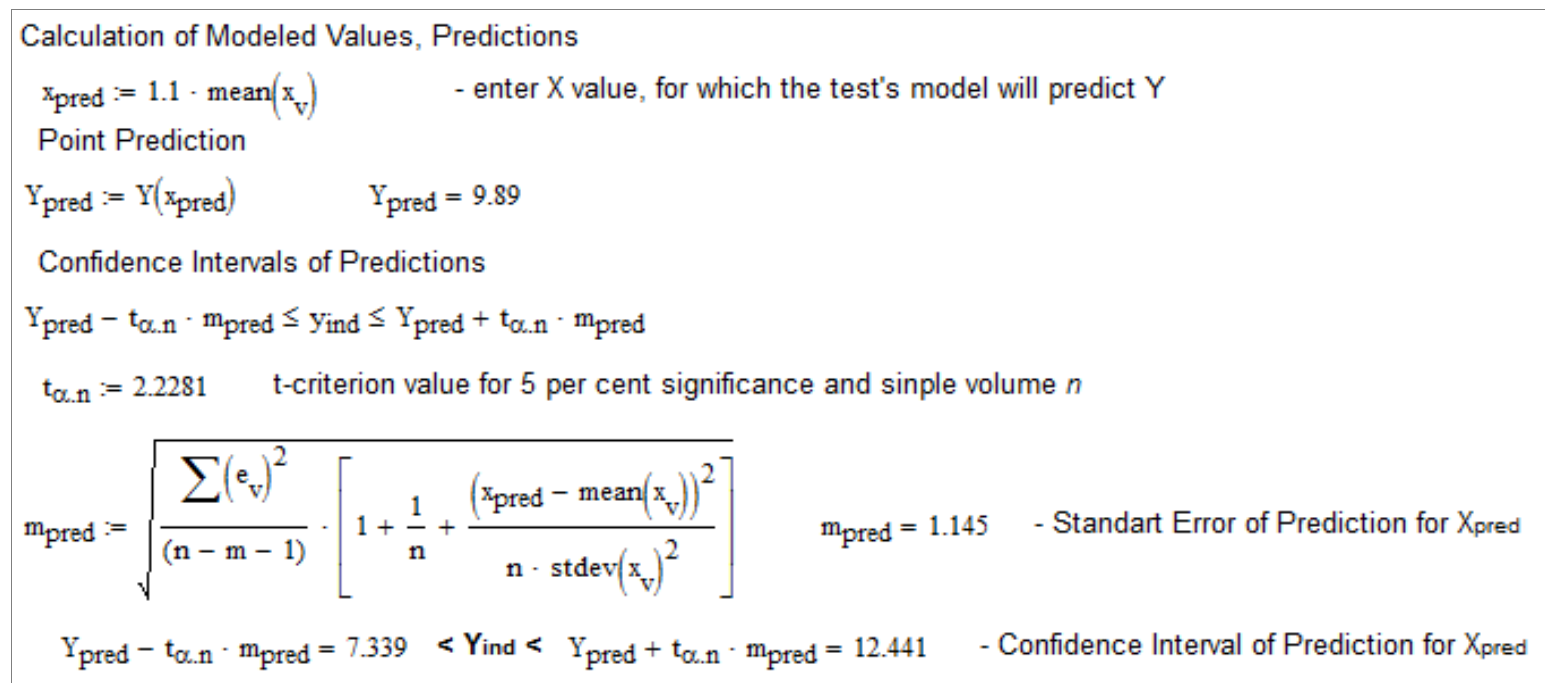

Figure 8. Automated prediction value calculation algorithm and an example of its implementation for calculating the required variant.

Source: author's research. 


\section{DISCUSSION AND PROSPECTS FOR RESEARCH}

The approach to automating students' independent work and monitoring their knowledge and skills, and the algorithm developed for this purpose and described in the research using the example of Linear Pair Regression, can easily be adapted to other conditions as well. For example, it is possible to generate samples in which Gauss-Markov conditions are broken down, that is, samples in which the residuals are heteroskedastic and/or autocorrelated. In this case, students can practice their skills in checking sample data against the Gauss-Markov theorem conditions. Figures 9 and 10 show examples of possible adjustments to the algorithm, which allow the data to be generated with inherent breakdowns of the conditions for the random components. These figures illustrate the two most common types of possible heteroscedasticity and correlation: increasing and decreasing ones. Figure 11 also shows their corresponding correlation field diagrams.

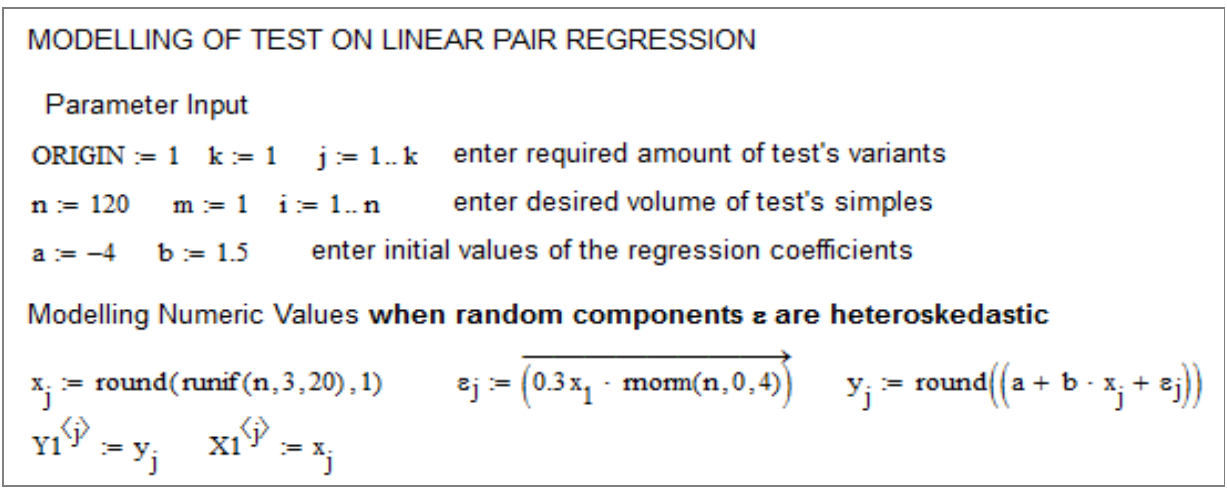

Figure 9. Example of algorithm adjustment to generate data with increasing type of heteroskedasticity of random components. Source: author's research.

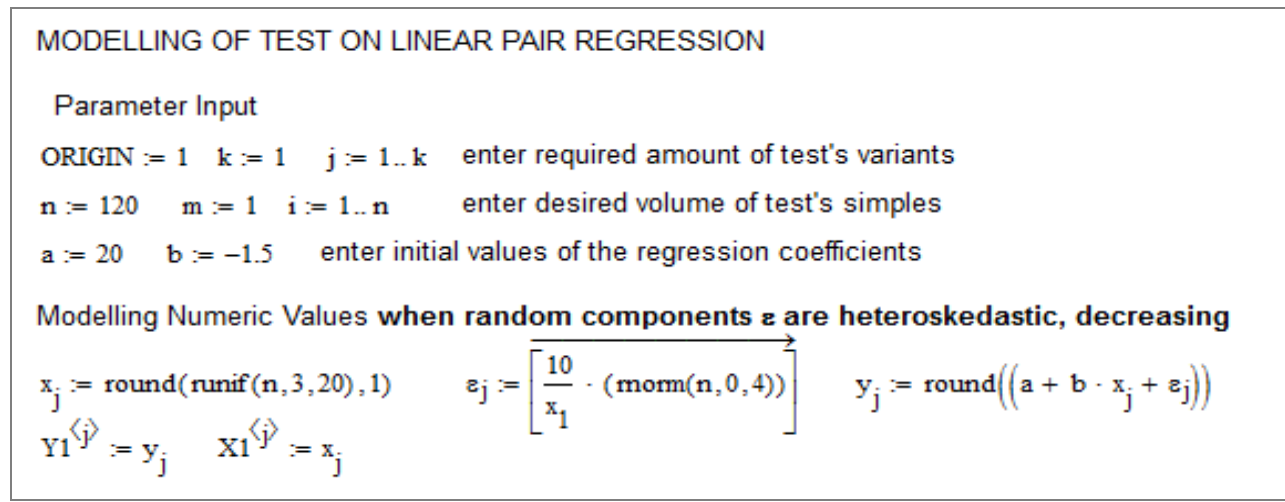

Figure 10. Example of an algorithm adjustment to generate data with a decreasing heteroskedasticity type of random components. Source: author's research.

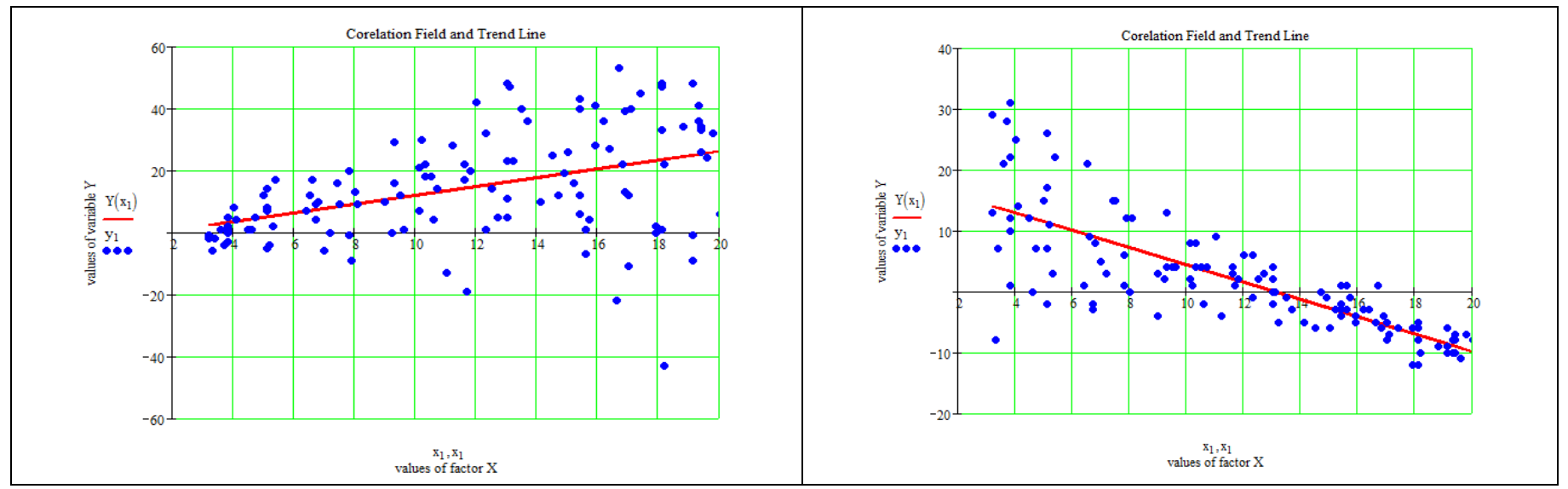

Figure 11. Examples of generated data with increasing and decreasing heteroscedasticity types of random components. Source: author's research. 
In addition, this approach can be extended with appropriate adjustments to other topics. So, for example, if we replace the expression for a linear model with a non-linear function and make appropriate changes in the task text and some adjustments in the developed algorithm, we will obtain an algorithm for automated creation of tasks and their checking to study non-linear regression. Similarly, if we add the generation of values for several factors $X$ to the algorithm and make the appropriate corrections to the calculations, we will obtain an algorithm for automated creation and testing multiple linear regression tests.

Thus, the proposed approach and algorithm can be adapted not only for other topics in "Econometrics" and "Mathematical Statistics", but also for other mathematical disciplines.

\section{CONCLUSION}

The approach presented in the study and the algorithm developed to automate data creation for a large number of tasks and test variants, their calculations, and also for displaying solutions (by the example with econometric tests) significantly saves time and costs for the organization of training and knowledge control.

In addition, the proposed approach and algorithm in an online learning environment expand the opportunities for independent students' work. Using this kind of algorithm and approach, students can quickly get a large number of learning and training tasks for self-monitoring as well as for preparation for tests and examinations $[3,4,5,11]$.

On the other hand, teachers are freed from time-consuming routine work on the development and check tasks completed and can direct their efforts to perform high-quality scientific research; to improve their methodological skills and the content quality of the discipline taught; to search and calculate more interesting applied examples for lectures and practical classes [16]. As a result, the quality of students' education and the quality of teachers' and universities' work are improved.

The effectiveness of the developed approach to automating the creation of econometric test tasks and monitoring students' knowledge is confirmed by its successful practical application by the author in the course of educational and methodological work in Russian universities. The developed algorithm has been registered by the Federal Service for Intellectual Property of the Russian Federation. The author received "Certificate of State Registration of a Computer Software "Software Application for Automated Simulation of Econometric Models of Linear Regression with One Regressor in MathCad 15 System" No. RU2020665996 dated 03.12.2020 [17] for this invention.

\section{APPENDIX}

Figure 12 shows the translation from Russian into English of the Certificate issued to the author confirming that the invention presented in the paper is patented and has the Certificate on the state registration in the Russian Federation.

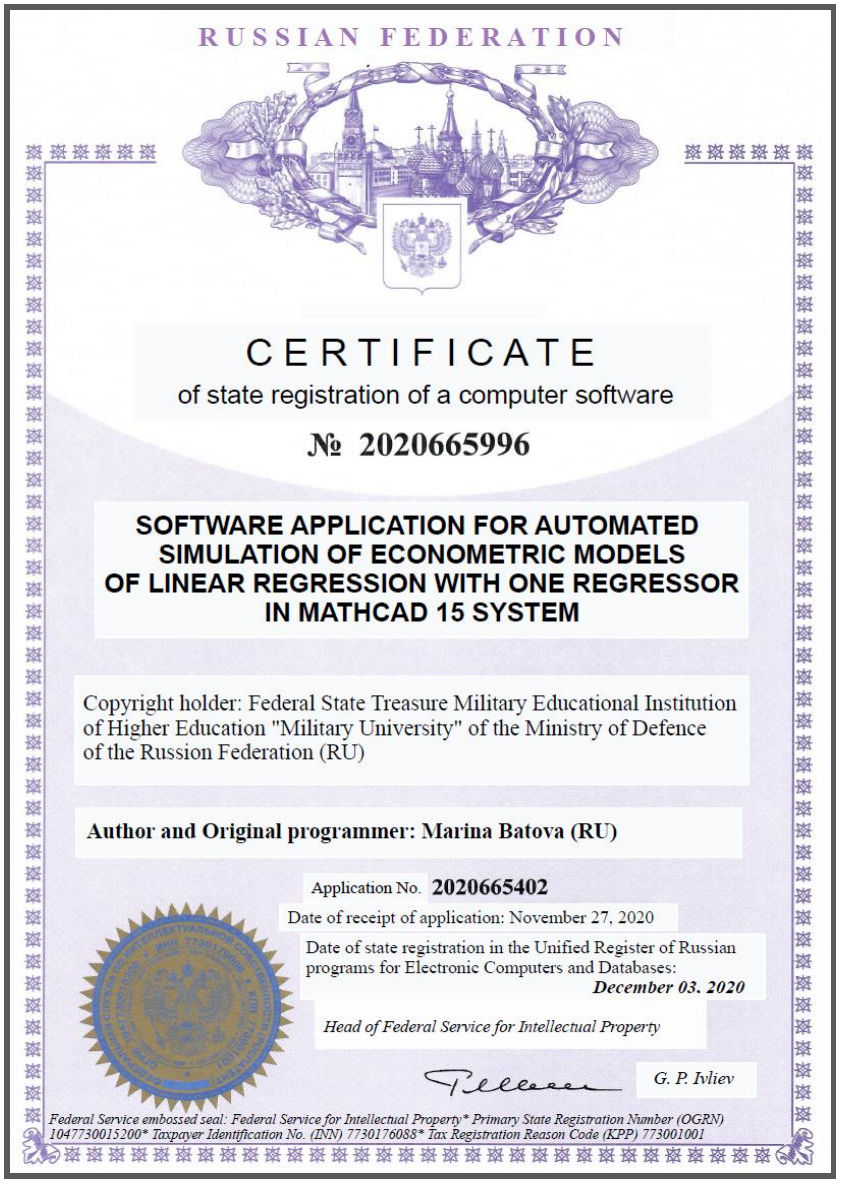

Figure 12. Translated copy of the Certificate of State Registration issued to the author.

\section{References}

[1] M. M. Batova, "Formation of digital competencies in the system "education - science - production", Issues of innovative economy, vol.9. (4), 2019, pp.1573-1584. doi: 10.18334/vinec.9.4.41467 (in Russian).

[2] C. J. Brame and R. Biel, "Test-enhanced learning: the potential for .testing to promote greater learning in undergraduate science courses". CBE Life Sci Educ. 2015 Summer; 14(2):14:es4. doi: 10.1187/cbe.14-11-0208. PMID: 25999314; PMCID: PMC4477741.

[3] J. C. Brame, Science Teaching Essentials. Short Guides to Good Practice, 2019, Academic Press - Elsevier. doi.org/10.1016/C2017-0-01010-8.

[4] D. Laurillard., "Effective Use of Technology in Teaching and Learning in HE" in International Encyclopedia of Education, 3ird ed., P. Peterson, E. Baker and B. McGaw Eds. , Academic Press - Elsevier, 2010, pp.419-426. doi.org/10.1016/B978-0-08-044894-7.00867-8.

[5] M. J. Nathan, "Technology Supports for Acquiring Mathematics" in International Encyclopedia of Education, 3ird ed., P. Peterson, E. Baker and B. McGaw Eds., Academic Press - Elsevier, 2010, pp. 172-183. doi.org/10.1016/B978-0-08-044894-7.00735-1.

[6] N. Entwistle Student Learning and Academic Understanding. A Research Perspective with Implications 
for Teaching, Academic Press - Elsevier, 2018, pp.175197. doi.org/10.1016/C2014-0-02037-0.

[7] L.Verschaffel, F. Depaepe and T. De Corte, "Mathematics Education" in International Encyclopedia of the Social \& Behavioral Sciences, 2nd ed., J. D. Wright Ed., Academic Press - Elsevier, 2015, pp. 816-821, doi.org/10.1016/B978-0-08-097086-8.92048-8.

[8] B. P.Veldkamp, "Computerized Test Construction" in International Encyclopedia of the Social \& Behavioral Sciences, 2nd ed., J. D. Wright Ed., Academic Press Elsevier, 2015, pp.510-514. doi.org/10.1016/B978-0-08097086-8.43019-9.

[9] A. G.Hoffmann, "Artificial and Natural Computation" in International Encyclopedia of the Social \& Behavioral Sciences, 2nd ed., J. D. Wright Ed., Academic Press Elsevier, 2015, pp. 27-31, doi.org/10.1016/B978-0-08097086-8.43004-7.

[10] T. Moore, Y. Doerr, and A. Glancy, "Approaches to Teaching Mathematics Through Modeling” iIn: Borromeo R. Ferri and W. Blum Eds., Lehrerkompetenzen zum Unterrichten mathematischer Modellierung. Realitätsbezüge im Mathematikunterricht. Springer Spektrum, Wiesbaden, 2018. doi.org/10.1007/978-3-65822616-9_10.

[11]S. Hauk et al. "Research in Collegiate Mathematics Education" in: A. Deines, D. Ferrero, E. Graham, M. Im, C. Manore, and C. Price, Eds., Advances in the Mathematical Sciences. AWMRS 2017. Association for Women in Mathematics Series, vol 15. Springer, Cham, 2018. doi.org/10.1007/978-3-319-98684-5_14.
[12] A. James, Methods of Teaching Mathematics, Neelkamal Publications, 2016.

[13] W. H. Greene, Econometric Analysis, 8th ed, Prentice Hall, 2017.

[14] Y. Hong, Foundations of Modern Econometrics. A Unified Approach, Singapure, World Scientific, 2020. doi.org/10.1142/11824.

[15]B. Maxfield, Essential PTC ${ }^{\circledR}$ Mathcad Prime ${ }^{\circledR}$ 3.0. 1st ed., A Guide for New and Current Users, 2013, Academic Press - Elsevier.

[16]H. Tijms Chapter 5: "Computer Simulation and Probability" in Basic Probability. What Every Math Student Should Know, Singapure, World Scientific, 2019, pp. 89-109. doi.org/10.1142/9789811202360_0005.

[17] M. Batova, Certificate of state registration of the computer program "Program for automated simulation of econometric models of paired linear regression in MathCad 15" No. RU2020665996, issued by Federal Service for Intellectual Property of the Russian Federation, Moscow, 03.12.2020. https://new.fips.ru/iiss/document.xhtml?facesredirect=true \&id=c8230a459e8b1496a20b69857f037069. (in Russian).

\section{Creative Commons Attribution License 4.0 (Attribution 4.0 International, CC BY 4.0)}

This article is published under the terms of the Creative Commons Attribution License 4.0 https://creativecommons.org/licenses/by/4.0/deed.en US 